Check for updates

Cite this: RSC Adv., 2018, 8, 19389

Received 20th February 2018 Accepted 17th May 2018

DOI: $10.1039 / c 8 r a 01539 b$

rsc.li/rsc-advances

\section{Traversing the profile of biomimetically nanoengineered iron substituted hydroxyapatite: synthesis, characterization, property evaluation, and drug release modeling $\dagger$}

\author{
Lubna Sheikh, (DD abc Shivendra Sinha, ${ }^{\text {ac }}$ Y. N. Singhababu, ${ }^{\text {ac }}$ Vineeta Verma, ${ }^{\text {b }}$ \\ Sucheta Tripathy ${ }^{\mathrm{ab}}$ and Suprabha Nayar ${ }^{\star a c}$
}

Even though ion substituted hydroxyapatite nanoparticles are associated with promising features for biomedical applications, green synthesis with precise control of size and shape to produce uniform nanoparticles remains elusive. To overcome this, we herein propose a room temperature, biomimetic approach to synthesize iron substituted nano-hydroxyapatite (m-HA) along with thorough physicochemical and biological evaluation. The study revealed that $10 \%$ iron could be isomorphously doped into hydroxyapatite crystal structure. Stress, strain, energy density and atomic occupancy, as a result of substitution, have been ascertained by Williamson-Hall and Rietveld analysis using X-ray diffraction data. X-Ray photoelectron spectroscopy has been employed to confirm the elemental composition, chemical state and environment of m-HA. In addition, vibrating sample magnetometer of $\mathrm{m}-\mathrm{HA}$ shows a trend towards superparamagnetic behaviour. Further, fluorescence assisted cell sorting and scanning electron microscope studies confirmed increase in the cell density with increasing iron concentration. Excellent antibacterial property, enhanced biocompatibility and bioactivity have also been interestingly observed. More controlled and sustained drug release has been observed with the inclusion of iron. A mathematical model developed to elucidate drug diffusion coefficient reveals Fickian mechanism to govern the release profile up to 8 hours followed by a non-Fickian transport. With these distinct features, this versatile material holds immense potential as bone repair material for osteoporosis where targeted delivery of calcium is required, as a heating mediator in cancer treatment and as a vehicle for site specific delivery of drug.

\section{Introduction}

Hydroxyapatite $\left[\mathrm{Ca}_{10}\left(\mathrm{PO}_{4}\right)_{6}(\mathrm{OH})_{2}, \mathrm{HA}\right]$, a cutting edge material in various orthopedic and orthodontic industries, is endowed with excellent properties like bioactivity, biocompatibility, ability to promote cellular functions, and osteoconductivity. ${ }^{\mathbf{1 - 4}}$ Due to the chemical and structural similarity with the mineral phase of bone and teeth, this inorganic phosphate has attracted significant attention for medical applications in the form of powders, composites and coatings. ${ }^{5-9}$

In spite of the afore mentioned properties, synthetic HA finds limited application as a bone graft material owing to several challenges such as optimum level of crystallinity, phase purity, high in vitro solubility and low mechanical

${ }^{a}$ Academy of Scientific and Innovative Research (AcSIR), Ghaziabad-201 002, India ${ }^{b}$ CSIR-Indian Institute of Chemical Biology, Kolkata, India

${ }^{c}$ CSIR-National Metallurgical Laboratory, Jamshedpur-831007, India. E-mail: suprabha.nayar@gmail.com

$\dagger$ Electronic supplementary information (ESI) available. See DOI: 10.1039/c8ra01539b properties. ${ }^{\mathbf{1 0 - 1 3}}$ Intensive research is under way to synthesize HAmetal composite or ion substituted-HA by different methodologies to overcome the above challenges. ${ }^{14-18}$ Among these methods, ionic substitutions emerged as a powerful tool for improving the performance of HA, either through modifications of the chemical, structural, and morphological characteristics or through utilizing the therapeutic properties of the substituting ions. ${ }^{19-22}$ The unit cell of stoichiometric crystalline hydroxyapatite hosts 10 cations arranged in two non-equivalent positions: four at the $\mathrm{M}(1)$ site aligned in the column, each surrounded by nine oxygen atoms, and six at the $\mathrm{M}(2)$ site arranged at the apexes of "staggered" equilateral triangles, each surrounded by seven oxygen atoms, which is depicted in Fig. 1(a) and (b)..$^{\mathbf{1 , 2 , 8 , 2 3 - 2 5}}$ This is what makes the apatite structure relatively flexible and stable, helping it to lend itself for a range of cationic and anionic substitution like $\left(\mathrm{Mg}^{2+}, \mathrm{Zn}^{2+}, \mathrm{Sr}^{2+}, \mathrm{Fe}^{2+}\right)$ and/or like $\left(\mathrm{SiO}_{4}{ }^{4-}, \mathrm{F}^{-}, \mathrm{CO}_{3}{ }^{2-}\right)$ respectively. Even though the extent of these isomorphous substitutions is minimal, but they greatly tune many of the properties of HA like biological activity, interaction between bone mineral and calcium-phosphate- 


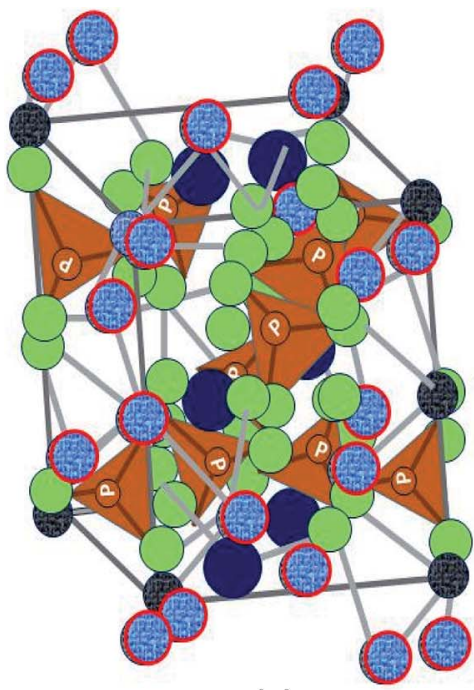

(a)

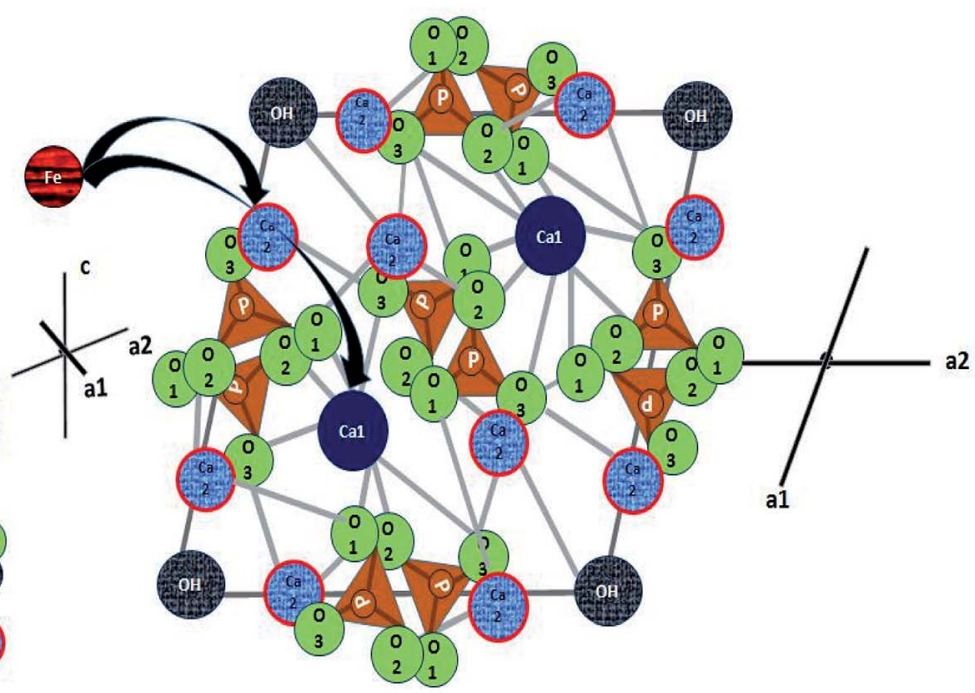

(b)

Fig. 1 Schematic representation of the possible way of substitution (a) HA unit cell and (b) (001) plane to have an inflated view.

based implant materials by influencing crystal growth, drug delivery efficiency, dissolution rate, solubility, surface chemistry and charge, morphology, and the mechanical properties..$^{26-28} \mathrm{As}$ for example Webster et al. and Ito et al. have shown that the doping of the bivalent and trivalent metal cations such as $\mathrm{Mg}^{2+}$, $\mathrm{Zn}^{2+}, \mathrm{La}^{3+}, \mathrm{Y}^{3+}, \mathrm{In}^{3+}$, and $\mathrm{Bi}^{3+}$ enhance the adherence and differentiation of bone-forming cells at a faster rate compared to un-doped HA..$^{26,27}$ Among the various cations that can replace calcium in HA, iron provokes an increasing interest as it is a biologically essential component for majority of cellular and enzymatic functions. And most importantly, the substitution of iron in HA is of great value as these substitutions not only enhances the functional properties but also introduces the magnetic property in HA that gives an additional edge to its applications as a heating mediator in hyperthermia therapy for cancer treatment ${ }^{29}$ and site specific drug delivery that can be manipulated with the help of external magnetic field.

Though some groups have tried substitution of $\mathrm{Ca}^{2+}$ ions in HA with $\mathrm{Fe}^{2+} / \mathrm{Fe}^{3+}$ ion using different techniques ${ }^{30-32}$ like wet chemical, sol-gel, hydrothermal, microwave etc., these methods suffer from the involvement of multi-step, energy intensive route, constrained environment, risk of using reactive $\mathrm{H}_{2}$ gas, decreased crystallinity as a function of iron content and precipitation of secondary phases (like hematite or magnetite). The solution to the abovementioned challenges was achieved by an interesting approach termed "biomimetic" that underpins the present study. This is a one pot, green, scalable, and cost effective process to synthesize phase pure iron doped HA. This involves organic matrices which could either be of natural or synthetic origin which help to offset the thermodynamic limitations by establishing kinetic control on nucleation and growth of the crystals, leading to the generation of materials with optimum crystallinity and stringent control over its size. In spite of some reports on ways to synthesize iron substituted HA, only few reports pertaining to the site occupancy of the substituent in HA crystal and the effect of dopant/substituent concentration on the functional properties of $\mathrm{HA}$ is available. In order to have a deeper knowledge of the same, a detailed study with different iron concentration was carried out.

In the present study, iron substituted hydroxyapatite nanoparticles were synthesized through biomimetic route via wetchemical precipitation method. The effect of iron incorporation on the structural (phase, crystallinity, crystal size, crystal lattice, stress and strain), functional, and biological properties of the resulting iron doped hydroxyapatite (m-HA) were evaluated by various analytical techniques like X-ray diffraction (XRD), X-ray photoelectron spectroscopy (XPS), Fourier-transform infrared spectroscopy (FT-IR), Thermal Gravimetric Analysis (TGA), Vibrating Sample Magnetometer (VSM), and Transmission Electron Microscopy (TEM). m-HA samples were also checked for their biocompatibility, antibacterial property, drug releasing capability, cell morphology in due time, cell adhesion and division on human osteosarcoma cells (MG-63). In order to complement the drug release profile, a mathematical expression was derived to calculate the diffusion coefficient using Fick's law. This model helped to elucidate the mechanistic information of drug release. The overall results indicate the exemplary behaviour of biomimetically nanoengineered m-HA having controlled and sustained drug release capability along with excellent antibacterial properties, improved bioactivity and non-toxicity. Thus, this study also offers a promising route for the synthesis of iron-substituted HA with excellent functional properties which further extends the space of its applications.

\section{Materials and method}

HA and m-HA powders were biomimetically synthesized at ambient reaction conditions. HA powder was prepared by adding an alkaline solution of calcium nitrate (pH-9.5) to the organic matrix which was $0.5 \mathrm{wt} \%$ of PVA. These solutions were equilibrated for a day followed by addition of di-ammonium hydrogen phosphate and ammonia solution. The obtained precipitation was HA, which is described by the following reaction: 


$$
\begin{gathered}
10 \mathrm{Ca}\left(\mathrm{NO}_{3}\right)_{2} \cdot 4 \mathrm{H}_{2} \mathrm{O}+6\left(\mathrm{NH}_{4}\right)_{2} \mathrm{HPO}_{4}+2 \mathrm{NH}_{4} \mathrm{OH} \rightarrow \\
\mathrm{Ca}_{10}\left(\mathrm{PO}_{4}\right)_{6}(\mathrm{OH})_{2}+20 \mathrm{NH}_{4} \mathrm{NO}_{3}+46 \mathrm{H}_{2} \mathrm{O}
\end{gathered}
$$

m-HA of different composition $\left(\mathrm{Ca}_{10-x} \mathrm{Fe}_{x}\left(\mathrm{PO}_{4}\right)_{6}(\mathrm{OH})_{2}\right),(0.2 \leq$ $x \leq 1.0$ ) was prepared, assuming that iron ions would substitute for calcium in the HA lattice in order to obtain a nominal composition in term of $(\mathrm{Ca}+\mathrm{Fe}) / \mathrm{P}$ ratio of 1.67 . m-HA powders were synthesized exactly the way HA was synthesized, described above other than addition of iron(III) nitrate $\left(\mathrm{Fe}\left(\mathrm{NO}_{3}\right)_{3} \cdot 9 \mathrm{H}_{2} \mathrm{O}\right)$ to calcium nitrate solution in different concentrations. The precipitation of m-HA occurred in the following manner:

$$
\begin{gathered}
(10-x) \mathrm{Ca}\left(\mathrm{NO}_{3}\right)_{2} \cdot 4 \mathrm{H}_{2} \mathrm{O}+x \mathrm{Fe}\left(\mathrm{NO}_{3}\right)_{3} \cdot 9 \mathrm{H}_{2} \mathrm{O}+6\left(\mathrm{NH}_{4}\right)_{2} \mathrm{HPO}_{4}+ \\
2 \mathrm{NH}_{4} \mathrm{OH} \rightarrow \\
\mathrm{Ca}_{10-x} \mathrm{Fe}_{x}\left(\mathrm{PO}_{4}\right)_{6}(\mathrm{OH})_{2}+20 \mathrm{NH}_{4} \mathrm{NO}_{3}+(4+4 \\
(10-x)+9 x) \mathrm{H}_{2} \mathrm{O} \text { where, } 0.2 \leq x \leq 1.0
\end{gathered}
$$

HA along with 5 different sets of m-HA were synthesized. The concentrations of iron were $0 \mathrm{M}$ (control), $0.005 \mathrm{M}, 0.01 \mathrm{M}$, $0.015 \mathrm{M}, 0.02 \mathrm{M}$ and $0.025 \mathrm{M}$ and the samples were named as $0 \%, 2 \%, 4 \%, 6 \%, 8 \%$ and $10 \%$ respectively.

All the above precipitates were aged for 7 days, washed thoroughly to bring down the $\mathrm{pH}$ to neutral, filtered and finally dried in oven at $60{ }^{\circ} \mathrm{C}$ after which it was crushed and used for further characterizations.

\section{Drug release study}

$0.5 \mathrm{~g}$ of the different HA powders were mixed evenly with $0.5 \mathrm{mg}$ methotrexate drug and were then pressed into pellets and the average weight for each sample was recorded by using a tabulating machine since all the experiments were done in triplicate. Different HA scaffolds (square shaped with $1 \mathrm{~cm}(l)$ $\times 1 \mathrm{~cm}(b) x \times 0.2 \mathrm{~cm}(w)$ dimensions) loaded with $0.5 \mathrm{mg}$ of drug were transferred into $100 \mathrm{ml}$ dissolution medium consisting of a freshly prepared phosphate buffer saline, and the solution was stirred at a speed of $100 \mathrm{rpm}$ at $37{ }^{\circ} \mathrm{C}$. Three milliliter aliquots were withdrawn at predetermined time intervals for all the batches and absorbance (305 nm) was noted. For each sample withdrawn, an equivalent volume of phosphate buffer was added to the dissolution medium to ensure perfect sink conditions maintained throughout. The release profiles of all the batches were examined for 7 days (144 h) at 1 day interval and difference in the absorbance was recorded by a spectrophotometer. The amount of the drug released was obtained from the calibration curve and was fitted in a mathematical model, derived for our system to determine the diffusion coefficient of different samples. The mathematical derivation of the equation describing the calculation of diffusion coefficient is given in Section 1 of ESI. $\dagger$ The equation thereof is given as:

$$
\left[\frac{M_{t}}{M_{\infty}}\right]=\sqrt{\frac{243 C_{\mathrm{S}} D_{\mathrm{d}} t}{40 a^{\mathrm{o}^{2}} A}}
$$

where $\frac{M_{t}}{M_{\infty}}$ is release fraction, wherein $M_{t}$ represent \% drug leached at time $t$ and $M_{\infty}$ is the \% drug leached at infinite time (taken as 100); $A$ is the total amount of the drug present in the matrix per unit volume, $t$ is the time taken, $a^{\mathrm{o}}$ is the drug dimension, $D_{\mathrm{d}}$ is the drug diffusivity and $C_{\mathrm{S}}$ is the solubility of drug in the permeating fluid.

The diffusion coefficients of the different HA samples (i.e. undoped and doped) were calculated by using the release profile data of the different samples up to 8 hours as a function of square root of time as the release is governed by Fickian transport up to initial 8 hours. From the linear fitting of this plot the value of slope i.e. $\sqrt{243 C_{\mathrm{S}} D_{\mathrm{d}} / 40 a^{\mathrm{o}^{2} A}}$ can be obtained. Therefore, the diffusion coefficient can be calculated from $D=$ slope ${ }^{2} / 0.0121$.

\section{Sample characterization}

Phase identification of powder sample was ascertained by room temperature XRD in D8 DISCOVER BRUKER Diffractometer, with $\mathrm{Cu}-\mathrm{K} \alpha(\lambda=1.5418 \AA)$ source, radiation generated at $40 \mathrm{kV}$ and $40 \mathrm{~mA}$ within scanning range of $20-60^{\circ}(2 \theta)$ at step size of $0.02^{\circ}$ per step, scanning rate of $5 \mathrm{~s}$ per step. Further, the Rietveld refinement of the control and $2 \% \mathrm{~m}$-HA have been carried out using Maud software to verify the site occupancy of iron. The initial refinement was performed using the reported CIF file ${ }^{33}$ followed by the refinements of the lattice parameters, crystallite size and atomic positions till the refinement is converged. XPS was carried out in ESCA system M/s SPECS with $\mathrm{Mg}$ twin (1253.6 eV) source. The vacuum of the chamber was better than $10^{-9}$ torr while recording the spectra. The spectrum was deconvoluted by using CASA XPS software to identify the chemical state and chemical composition. Prior to curve fitting, the background was subtracted from each spectrum by the Shirley method. The binding energy scale was calibrated for electrostatic charging w.r.t. the standard C1s peak at $284.6 \mathrm{eV}$. The functional groups of the synthesized samples were identified by FTIR (Bruker Alpha P) using ATR method from 400$4000 \mathrm{~cm}^{-1}$. Thermal gravimetric analysis was performed using the (Linseis STA PT1600, USA), in 25-1000 ${ }^{\circ} \mathrm{C}$ temperature range, in air environment, with $\mathrm{Al}_{2} \mathrm{O}_{3}$ as reference. Structural investigation was carried out in analytical TEM, JEOL JEM 2010 using $200 \mathrm{kV}$ electron source. The samples for TEM study was prepared by dispersing different HA powders in ethanol by ultra-sonication in a low power ultrasonic cleaning bath (150 Watts, $40 \mathrm{kHz}$ ) for $30 \mathrm{~min}$. A single drop of the dispersion was dried on carbon coated copper grids ( $\sim 300$ mesh) and then viewed under the electron microscope. Surface morphology was studied by FESEM, FEI Nova Nano SEM 430 operated at $15 \mathrm{kV}$.

\section{Results and discussion}

\subsection{Characterization of HA and m-HA}

5.1.1 X-ray diffraction (XRD). XRD was employed to verify the formation of HA phase and changes in its crystal structure with the incorporation of iron by the adapted methodology. Fig. 2(a) is the XRD pattern of the synthesized HA and m-HA. The XRD pattern confirms the signature peaks of the HA phase. It has been concluded that a maximum of $10 \%$ of iron 
could be doped in HA crystal, by the adapted protocol because the phases pertaining to iron oxide peak starts appearing after $10 \%$ (see Fig. S3 of ESI $\dagger$ ). A careful observation of the XRD pattern reveals a shift in the peak position of m-HAs towards higher two theta value accompanied by an increase in the peak broadening as a function of iron concentration (Fig. 2(a)). To verify this, the graph (Fig. 2(b)) was plotted between (211) plane's peak position with respect to dopant concentration in $\mathrm{m}$-HA samples. The figure clearly enunciates that there is a shift in the peak position towards higher two theta value with an increase in doping concentration. The peak shift is attributed to shrinkage in the lattice parameter due to decrease in size of the nanoparticles by substitution of iron. This is because of the fact that size of $\mathrm{Fe}^{2+} / \mathrm{Fe}^{3+}(0.66 \AA)$ is smaller than $\mathrm{Ca}^{2+}(0.99 \AA){ }^{34}$ Hence, the slight peak shift to higher two theta is an indirect evidence of iron substitution in HA crystals. ${ }^{35,36}$ In such cases the lattice parameters and the crystallite size of the doped HA gets reduced as compared to the control, leading to the generation of strain in the doped crystal.

Indeed, Williamson Hall (W. H) equation of Uniform Deformation Model (UDM) is used, by and large, to calculate the average crystallite size, strain and strain energy density. ${ }^{37}$

The equation is given by

$$
\beta \cos \theta=\frac{k \lambda}{D}+4 \eta \sin \theta
$$

where $\beta$ is the peak width at half maximum intensity, $\theta$ is the peak position, $k$ is a constant equal to $0.94, \lambda$ is the wavelength of the radiation, $\eta$ is the strain and $D$ is the crystallite size in $\mathrm{nm}$. The value of $\beta$ is calculated using Fullprof 8.0. Further, uniform stress deformation model (USDM) and uniform deformation energy density model (UDEDM) were considered to account related stress and strain energy. The equation of the model is given by: ${ }^{37}$

$$
\begin{gathered}
\beta \cos \theta=\frac{k \lambda}{D}+\frac{4 \sigma}{Y_{h k l}} \sin \theta \\
\beta \cos \theta=\frac{k \lambda}{D}+\left(\frac{2 \mu}{Y_{h k l}}\right)^{0.5}(4 \sin \theta)
\end{gathered}
$$

where $\sigma$ is the stress of the crystal, $\mu$ is the energy density and $Y_{h k l}$ is the modulus of the elasticity or Young's modulus. Eqn (3) and (4) are an approximation of Hooke's law, which is significantly valid for small strain. Here, the assumption of small strain has been considered to calculate the stress and energy density. Since, HA comes under hexagonal crystal system, the Young's modulus is given by the following relation: where, $h k l$ are the indices, $S_{11}, S_{13}, S_{33}$ and $S_{14}$ are the elastic compliances of HA. The results obtained using W. H equation (UDM, USDM model and UDEDM model) are summarized in Table 1 and the values of $Y_{h k l}$ were calculated using Rietveld data. It can be noted from the table that the average crystallite size decreases with increase in doping concentration. More interestingly, negative values of stress and strain have also been observed that increases in magnitude with increase in concentration of iron doping (refer to Fig. S4-S6 of ESI $\dagger$ ). The negative value of strain, underpinned by the concept of decrease in lattice size, which, indeed, has been reported by Zak et al. and Gonclaves et al. ${ }^{37,38}$

The observance of such kind of behaviour in our case is attributed to the doping of iron in $\mathrm{HA}$ due to smaller of $\mathrm{Fe}^{2+} / \mathrm{Fe}^{3+}$ than $\mathrm{Ca}^{2+}$ that leads to the contraction of unit cell volume. By combining the results obtained from $\mathrm{W}$. $\mathrm{H}$ analysis, we concluded that iron is doped in the crystal structure of HA otherwise such type of trend in crystallite size, strain energy would not have followed.

After verifying the doping of iron in HA, we were further interested to know the atomic sites occupancy of iron and the change in the lattice parameter upon substitution. In view, the Rietveld refinement analysis of the control $\mathrm{HA}$ and 2\% m-HA have been carried out using Maud software. And it was concluded that either iron is substituted in the ' $\mathrm{Ca}$ ' sites (at $\mathrm{Ca}_{1}$ and $\mathrm{Ca}_{2}$ ) or at the tunnels (by replacing $\mathrm{OH}^{-}$ions). It is reported earlier that the substitutions in the tunnels lead to expansion in the unit cell volume while substitution in the Ca sites by a smaller cation results in the reduction of unit cell volume. In our case, a regular decrease in the unit cell volume accompanied by the peak shift to the higher two theta value has been observed with increase in the iron doping concentration. Such type of behaviour is a signature of substitution in Ca sites. ${ }^{33,34}$ This is in well agreement with our results (Fig. 2(c) and (d)). The detailed information drawn from the above analysis is summarized in Table 2. Overall the XRD results suggested that up to $10 \%$ iron can be doped in the HA structure without any sort of secondary phase formation, indicating the adapted protocol to be suitable for the synthesis of phase pure HA and m-HA.

5.1.2 X-ray photoelectron spectroscopy (XPS). XPS is a powerful surface technique that gives information about the chemical composition, atomic ratio $(\mathrm{Ca} / \mathrm{P}$ ratio), chemical linkage and chemical state of the elements present in the sample under investigation. Fig. 3 is the survey XPS spectrum of $\mathrm{HA}$ and m-HA samples. In the survey spectrum of $\mathrm{HA}$ the composition is $\mathrm{Ca}, \mathrm{P}$ and $\mathrm{O}$, while in case of $\mathrm{m}$-HA samples, the

$$
Y_{h k l}=\frac{\left[h^{2}+\frac{(h+2 k)^{2}}{3}+\left(\frac{a l}{c}\right)^{2}\right]^{2}}{S_{11}\left(h_{2}+\frac{(h+2 k)^{2}}{3}\right)^{2}+S_{33}\left(\frac{a l}{c}\right)^{4}+\left(2 S_{13}+S_{44}\right)\left(\left(h_{2}+\frac{(h+2 k)^{2}}{3}\right)^{2}\left(\frac{a l}{c}\right)^{2}\right)}
$$


Table 1 Geometric parameters of iron-doped HA samples

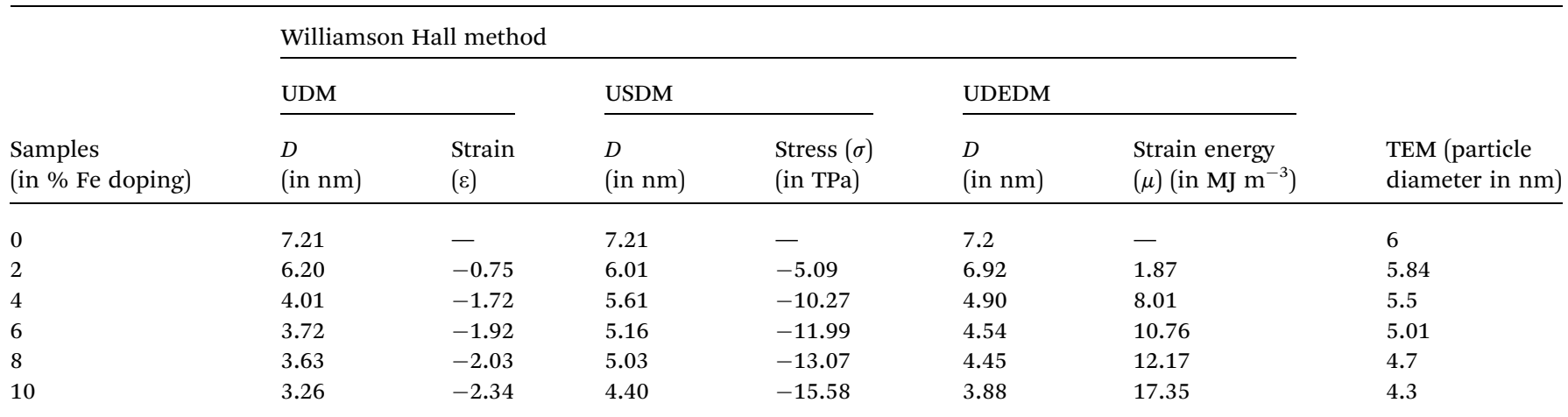
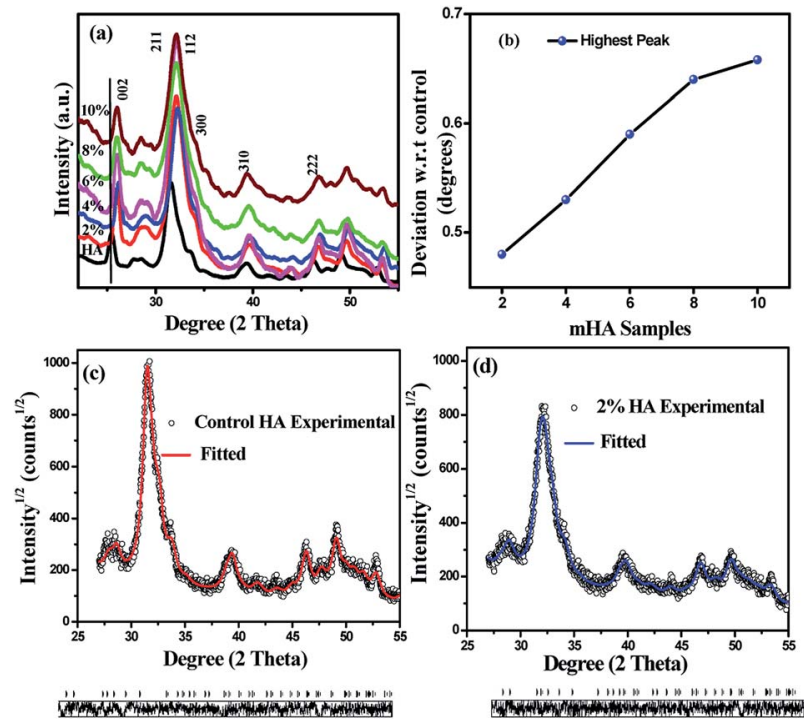

Fig. 2 (a) XRD pattern of $\mathrm{HA}$ and $\mathrm{mHA}$, (b) deviation of the (211) peak position of the $\mathrm{m}-\mathrm{HA}$ with respect to undoped $\mathrm{HA}$, (c) and (d) Rietveld refinement plot of control and $2 \% \mathrm{~m}-\mathrm{HA}$ respectively.

peaks corresponding to iron is also present. An immediate observation is that the intensity of Fe2p peak increases with increase in the dopant concentration indicating more iron incorporation in $\mathrm{HA}$. $\mathrm{Ca} / \mathrm{P}$ ratio was $1.67,1.642,1.638,1.606$, 1.592, and 1.571 from 0 to $10 \%$ respectively and in substituted $\mathrm{m}-\mathrm{HA}$ the $\mathrm{Ca}+\mathrm{Fe} / \mathrm{P}$ ratio was 1.67 further suggesting the maintenance of stoichiometry. In order to verify the chemical state and chemical linkage of the individual elements the high resolution XPS data are presented. The Ca2p peak appeared as a typical doublet peak due to spin-orbit coupling in all the cases. Fig. S7† depicts the deconvoluted Ca2p peak of the HA and m-HA samples where it fits only one peak each corresponding to $\mathrm{Ca} 2 \mathrm{p}_{3 / 2}$ and Ca2 $\mathrm{p}_{1 / 2}$ indicating the presence of only one type of calcium species. Further, the peak position and peak energy separation values indicated that ' $\mathrm{Ca}$ ' is in +2 oxidation state which was in well agreement with the chemical state of 'Ca' in HA. A slight peak shift of the Ca2p peak towards higher binding energy with increasing doping concentration is attributed to the increased concentration of iron in ' $\mathrm{Ca}$ ' sites showing substitution effect. Fig. $\mathrm{S} 8 \dagger$ is the deconvoluted P2p peak, which
Table 2 Rietveld refinement parameters of $\mathrm{HA}$ and $2 \% \mathrm{~m}-\mathrm{HA}$

\begin{tabular}{|c|c|c|c|c|c|c|c|}
\hline \multicolumn{2}{|c|}{ Samples } & \multicolumn{2}{|c|}{$a\left(\mathrm{~A}^{0}\right)$} & \multicolumn{2}{|c|}{$c\left(\mathrm{~A}^{0}\right)$} & \multicolumn{2}{|c|}{$\begin{array}{l}\text { Crystallite } \\
\text { size (nm) }\end{array}$} \\
\hline \multirow{2}{*}{\multicolumn{2}{|c|}{$\begin{array}{l}\mathrm{HA} \\
2 \% \mathrm{HA}\end{array}$}} & \multirow{2}{*}{\multicolumn{2}{|c|}{$\begin{array}{l}9.507 \\
9.408\end{array}$}} & \multirow{2}{*}{\multicolumn{2}{|c|}{$\begin{array}{l}6.927 \\
6.859\end{array}$}} & \multirow{2}{*}{\multicolumn{2}{|c|}{$\begin{array}{r}11.72 \\
9.44\end{array}$}} \\
\hline & & & & & & & \\
\hline HA & $\mathrm{Ca}_{1}$ & $\mathrm{Ca}_{2}$ & $\mathrm{P}$ & $\mathrm{O}_{1}$ & $\mathrm{O}_{2}$ & $\mathrm{O}_{3}$ & $\mathrm{O}_{4}$ \\
\hline$X$ & 0.333 & 0.233 & 0.403 & 0.324 & 0.590 & 0.351 & 0 \\
\hline$Y$ & 0.666 & -0.011 & 0.382 & 0.476 & 0.434 & 0.263 & 0 \\
\hline$Z$ & -0.003 & 0.249 & 0.249 & 0.249 & 0.249 & 0.069 & 0.224 \\
\hline \multicolumn{8}{|l|}{$2 \%$} \\
\hline HA & $\mathrm{Ca}_{1} / \mathrm{Fe}_{1}$ & $\mathrm{Ca}_{2} / \mathrm{Fe}_{2}$ & $\mathrm{P}$ & $\mathrm{O}_{1}$ & $\mathrm{O}_{2}$ & $\mathrm{O}_{3}$ & $\mathrm{O}_{4}$ \\
\hline$X$ & 0.334 & 0.242 & 0.401 & 0.336 & 0.603 & 0.341 & 0 \\
\hline$Y$ & 0.666 & 0.014 & 0.384 & 0.481 & 0.497 & 0.263 & 0 \\
\hline$Z$ & -0.002 & 0.250 & 0.250 & 0.250 & 0.250 & 0.072 & 0.286 \\
\hline
\end{tabular}

fits one peak, indicating the chemical environment around $\mathrm{P}$ is identical while the peak position corresponds to the phosphate group, as reported in our previous manuscript. ${ }^{13}$

In order to find out the chemical state of iron in doped HA, we present the Fe2p data of m-HA samples. Fig. 4(a)-(e) is the Fe2p spectrum of $2 \%, 4 \%, 6 \%, 8 \%$ and $10 \%$ m-HA samples. The peak position and peak energy separation are the two most important parameters to identify the chemical state of an element in the sample. The peak energy separation i.e. the

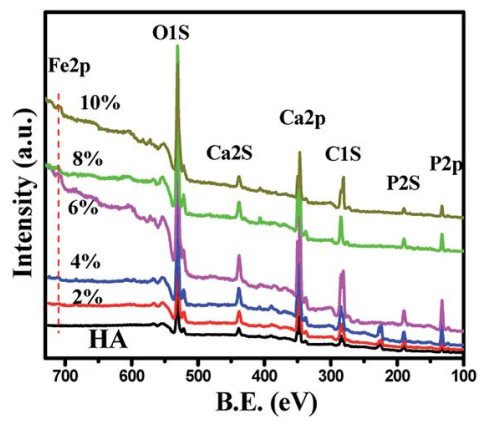

Fig. 3 Survey scan of HA and m-HA samples. 

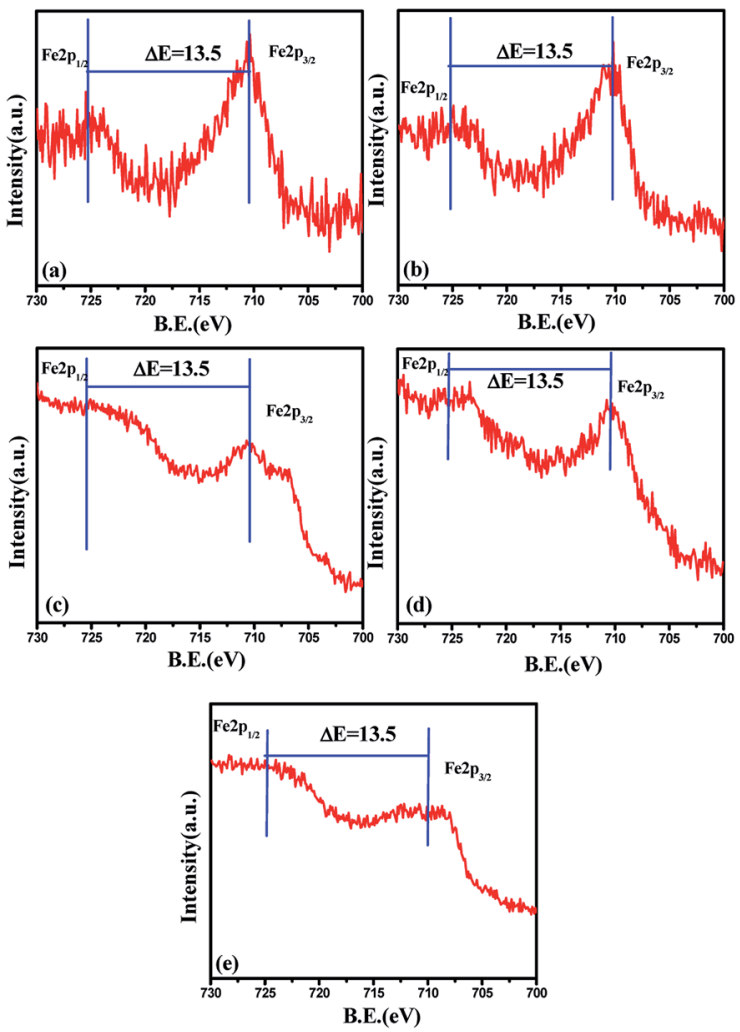

Fig. 4 (a), (b), (c), (d) and (e) are the Fe2p spectra of $2 \%, 4 \%, 6 \%, 8 \%$ and $10 \% \mathrm{~m}-\mathrm{HA}$ respectively.

energy difference between $\mathrm{Fe} 2 \mathrm{p}_{1 / 2}$ and $\mathrm{Fe} 2 \mathrm{p}_{3 / 2}$ is $13.5 \mathrm{eV}$ in all cases indicating iron to be in +3 oxidation state. Further, the appearance of $\mathrm{Fe} 2 \mathrm{p}_{3 / 2}$ peak appeared at $710.5 \mathrm{eV}$ further confirms the chemical state of iron ions is +3 in doped samples. $^{39}$

Hence, the XPS study reveals that pure m-HA sample can be synthesized unlike others where the m-HA contains other chemical species like carbonates indicating the uniqueness of our protocol.

5.1.3 Fourier transmission-infra red spectroscopy (FT-IR). Fig. 5 is the FT-IR spectra showing important functional groups of HA and subsequent changes with iron doping. The absorption band at $3570 \mathrm{~cm}^{-1}$ represents the stretching mode of vibration for the lattice $\mathrm{OH}$. The bands at 1032 and $1090 \mathrm{~cm}^{-1}$ belong to the triple degenerate $\nu_{3}$ asymmetric $\mathrm{P}-\mathrm{O}$ stretching mode while peaks at $960 \mathrm{~cm}^{-1}$ and $470 \mathrm{~cm}^{-1}$ corresponds to $\nu_{1}$ mode of non-degenerate $\mathrm{P}-\mathrm{O}$ symmetric stretching and doubly degenerate of $\nu_{2}$ bending of $\mathrm{O}-\mathrm{P}-\mathrm{O}$ mode respectively. The peak at 570 and $606 \mathrm{~cm}^{-1}$ are assigned to the triply degenerate $\nu_{4}$ bending of $\mathrm{O}-\mathrm{P}-\mathrm{O}$ mode. Altogether, almost all the bands associated with HA appeared in all the samples. Significant changes in the wave number and transmittance of $\mathrm{PO}_{4}{ }^{3-}$ and $\mathrm{OH}^{-}$were observed, indicating the 'substitution effect'. The decrease in transmittance of $\mathrm{O}-\mathrm{P}-\mathrm{O}$ stretching mode, at respective positions, suggests decrease in its dipole moment, which would be the consequence of electrostatic interaction of $\mathrm{P}-\mathrm{O}$ with substituted iron. The probable reason could be the presence of iron at $\mathrm{Ca}_{1}$ and $\mathrm{Ca}_{2}$ sites, decreases the polarity of

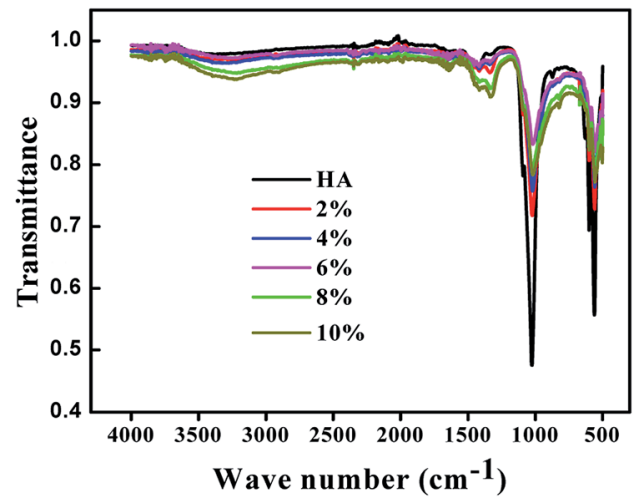

Fig. 5 FT-IR spectrum of $\mathrm{HA}$ and $\mathrm{m}-\mathrm{HA}$.

$\mathrm{P}-\mathrm{O}$ bond via columbic interaction with the electron density on oxygen atom. Furthermore, peak broadening has also been observed, which is ascribed to localized interaction with iron, which therefore resulted in different frequencies and wave numbers. However, no separate peaks were observed pertaining to iron related compounds, which succinctly tells the incorporation of iron in the matrix without secondary phase (i.e. iron oxide) formation.

5.1.4 Thermal behaviour of pure and m-HA. Fig. 6 illustrates the effect of iron on the thermal stability of the synthesized powders. There is a gradual decrease in weight loss up to $17 \%$ because of the absorbed water and the organic content used for synthesizing these nanoparticles. The initial mass loss is mainly caused by the water extrusion in lattice. This conclusion can be corroborated by the FTIR spectra where the pronounce appearance of the lattice $\mathrm{OH}$ peak was apparent. Though the total weight loss increased with increase in the iron content, the trend was similar to HA, indirectly illustrating the iron doping in HA. The destabilizing effect of iron is imputable
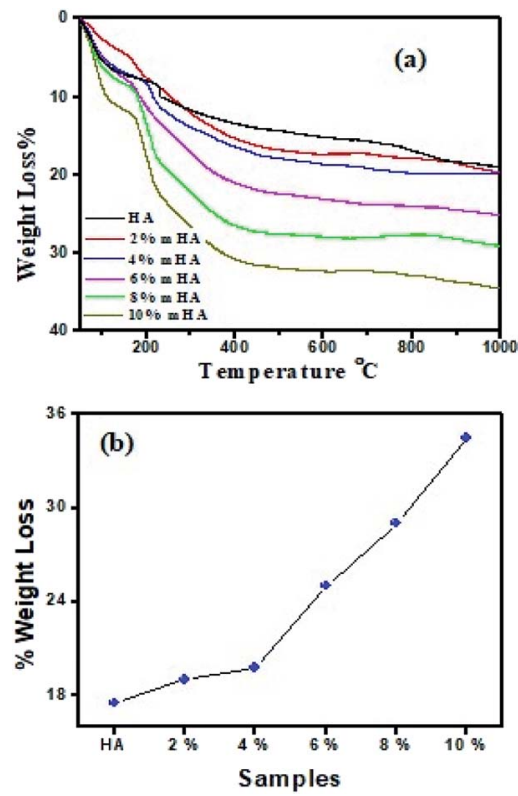

Fig. 6 (a) Temperature versus weight loss plot (b) trend of weight loss with increasing dopant concentration. 
to the smaller ionic radius of $\mathrm{Fe}^{3+}(0.66 \AA)$ with respect to $\mathrm{Ca}^{2+}$ (0.99 ̊). Other than this the thermal stability of m-HA showed a distinct weight loss compared to HA. The total weight loss was $17.5 \%$ for HA and $19 \%, 19.78 \%, 25 \%, 29 \%$ and $34.5 \%$ for $2 \%$, $4 \%, 6 \%, 8 \%$, and $10 \%$ m-HA respectively as shown in Fig. 6(b). This is probably because of the incorporation of iron ions which led to the transformation of HA into whitlockite in between temperature 300 to $1000{ }^{\circ} \mathrm{C}$, depending on the iron content as observed by Filho et al. ${ }^{\mathbf{4 0 , 4 1}}$

5.1.5 Transmission electron microscope (TEM). Fig. 7 depicts the microstructure of different samples. It is apparent from the images that as the concentration of iron increases there is a decreasing trend in the length of HA particles and acicular particles tends to transfer to spherical particles. Since HA crystal belong to the hexagonal system, the crystal grows along the $c$ crystal axis and causes acicular particles as seen in $0 \%$, Fig. 7(a). However, with increasing iron concentration, the grain sizes of HA particles in the direction of $c$-axis decreases. The monotonic decrease in the aspect ratio from 6.33 in $0 \%$ to 5.82 in $2 \%, 5.09$ in $4 \%, 4.14$ in $6 \%, 3.40$ in $8 \%$ and 3.02 in $10 \%$ was observed. The reason is that the ions replacement mainly occurs in $a$ plane, which causes the crystals growth along the $a$ axis. ${ }^{42}$ The results are in well agreement with the 002 peak intensity of XRD. Existence of independent iron oxide particles were not observed, suggesting no free iron in the system. The selective area diffraction pattern shows a polycrystalline ring pattern (inset) depicting the nanosized particles. The aggregates in the image may be attributed to the presence of iron which is probably introducing a directionality and alignment in the HA growth, which is clearly visible from $2-10 \%$ m-HA. In addition, there is a tendency for these HA nanoparticles to self-assemble into little stable assemblies, which further form islands of different irregular shapes.

\subsection{Property evaluation of $\mathrm{HA}$ and $\mathrm{m}-\mathrm{HA}$}

5.2.1 Magnetic property of m-HA. It is well known that HA is diamagnetic. ${ }^{43}$ Therefore, in order to check whether the doping of iron in HA by the adapted protocol has induced magnetism in HA or not, the magnetic property of the m-HA samples was evaluated at room temperature. Fig. 8(a), (b), (c), (d) and (e) shows the $M v s$.
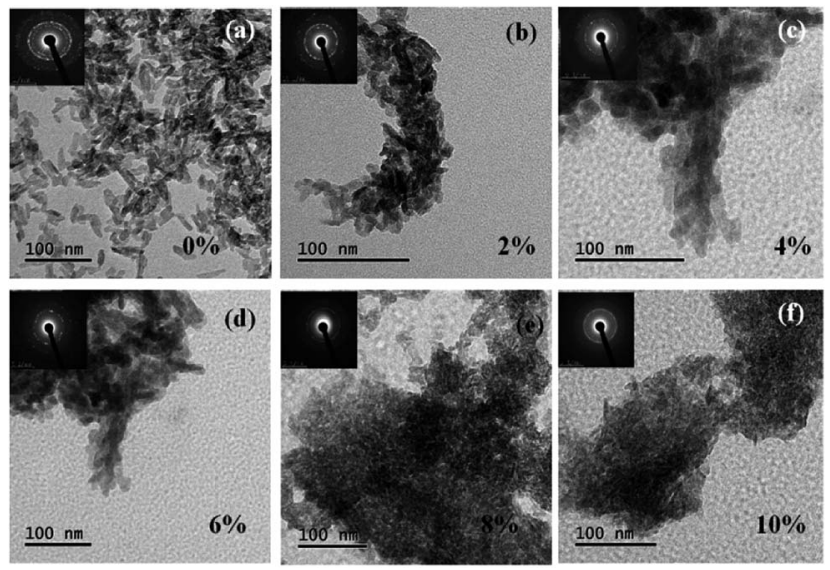
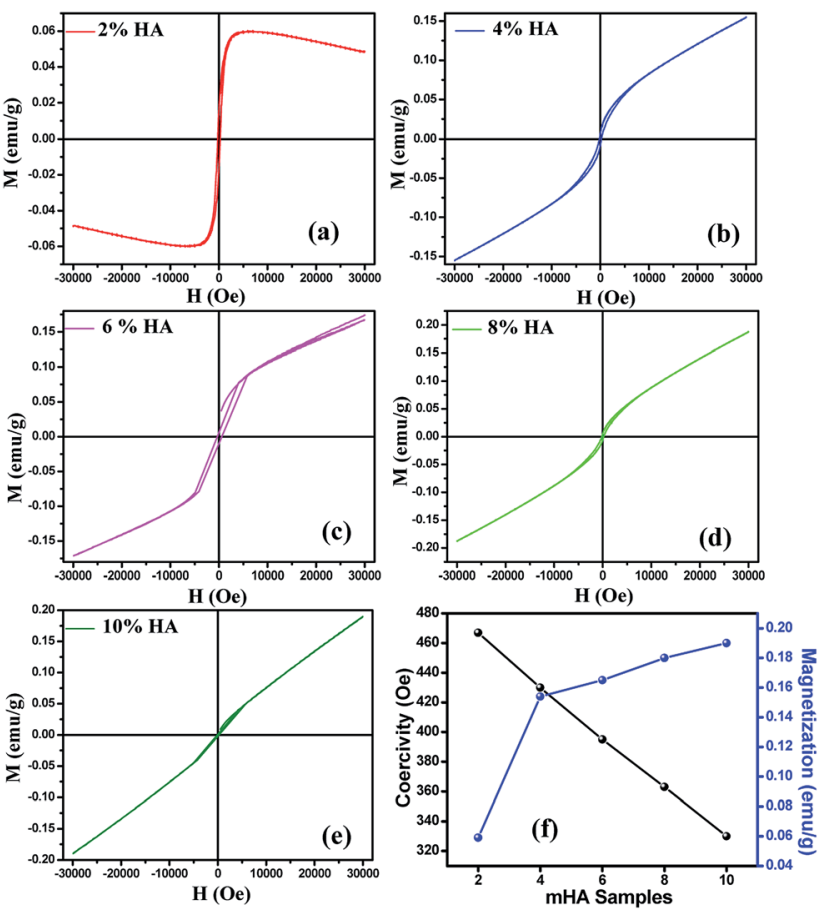

Fig. 8 (a)-(e) $M$ vs. $H$ plot of $m-H A$ samples, while (f) is the plot showing the variation of $H_{c}$ and $M_{s}$ value as a function of increasing doping concentration.

$H$ plot of $2 \%, 4 \%, 6 \%, 8 \%$ and $10 \%$ m-HA sample respectively, while (f) is the plot showing the variation of coercivity $\left(H_{\mathrm{c}}\right)$ and magnetization $\left(M_{\mathrm{s}}\right)$ value of m-HA sample as a function of increasing doping concentration. The coercivity and magnetization values of m-HA sample are reflected in Table 3 . In all cases a weak hysteresis loop is observed indicating super paramagnetic behavior of the m-HA samples. ${ }^{37}$

With increase in the iron concentration from $2 \%$ to $10 \%$, the following magnetic features are observed. First, the saturation magnetization increases and second, the coercivity decreases. The origin of magnetism in HA by doping of iron is neither well understood nor well reported. In fact, attempts have been made to understand the mechanism of such behavior by referring to the literature of magnetic HA and other known magnetic and non-magnetic materials.

It is well-known that the magnetism of any nanomaterial largely depends on the particle size, shape and composition. ${ }^{\mathbf{4 4}}$ Since the shape of all m-HAs are almost similar, therefore the shape effect is ruled out; the particle size and composition are the

Table 3 Summarizes the $H_{c}$ and $M_{s}$ values of $m-H A$ samples

\begin{tabular}{lll}
\hline m-HA & Coercivity (Oe) & $\begin{array}{l}\text { Magnetization } \\
\left(\mathrm{emu} \mathrm{g}^{-1}\right)\end{array}$ \\
\hline $2 \%$ & 467 & 0.059 \\
$4 \%$ & 430 & 0.154 \\
$6 \%$ & 395 & 0.165 \\
$8 \%$ & 363 & 0.18 \\
$10 \%$ & 330 & 0.19
\end{tabular}

Fig. 7 TEM micrographs of the synthesized nanoparticles. 
other two important governing factors in the observed phenomenon of increased magnetization and decreased coercivity with the increase in the dopant concentration. One of the plausible reasons for increased magnetization with decrease in the particle size could be that as the surface area to volume ratio increases, the total magnetic moment of the particle, arising from the contribution of surface spin. Thus results in the local disturbance of the spin orbit coupling and decreased magnetic anisotropy energy. These intrinsic effects reflect in a change of the coercivity.

5.2.2 Bactericidal activity of m-HA. After detailed physiochemical characterization of these magnetic nanoparticles we went ahead to check its biological performance. As iron is known for its antibacterial role so it was just curiosity that prompted us to check the antibacterial activity of m-HA's. And if these m-HAs show such type of property it will be a feather in cap because the need of novel antibiotics is of extreme importance, due to relatively higher incidence of bacterial infection and the growing resistance of bacteria to conventional antibiotics. Antibacterial efficacy of mHAs against both Gram-positive and Gram-negative bacterial strains viz. Escherichia coli and Staphylococcus aureus are shown in Fig. 9. The zone of inhibition produced by these nanoparticles against these bacteria were further compared with the standard gentamycin sulphate $\left(1 \times 10^{-3} \mu \mathrm{g} \mathrm{ml} \mathrm{m}^{-1}\right)$ disc that was used as a positive control.

Antibacterial activity results revealed that m-HA nanoparticles exhibited excellent antibacterial property against both Gram-positive and Gram-negative bacteria. The zone of inhibition was more intense in case of Gram positive. The compared to Gram negative and it increased with increase in the dopant concentration. This observation could also be indicative of higher Gram-negative strain resistance/tolerance against such nanomaterials over Gram-positive bacterial strains due to the presence of outer membrane. Increasing trend of antibacterial efficacy with increasing iron concentration shows that smaller the particle size, greater is the efficacy in inhibiting the growth of bacteria, involving both the production of reactive oxygen species and the accumulation of nanoparticles. ${ }^{45}$ The main mechanism by which the antibacterial drugs or antibiotics work is via oxidative stress generated by Reactive Oxygen Species (ROS) which can cause damage to proteins and DNA in bacteria. One of the reasons for this bactericidal activity may be due to the presence of $\mathrm{Fe}^{3+}$ ions, which must have reacted with oxygen to form hydrogen peroxide which consequently reacted with ferric ions via the Fenton reaction and produced hydroxyl radicals which is known to damage biological macromolecules. ${ }^{46,47}$ In addition, synergism to above reason could also be due to the penetration capability of smaller size of nanoparticles, which is more and that may eventually lead to more efficient disruption of the cell membrane. Hence, the antibacterial assay showed efficacy against the common pathogens $E$. coli and $S$. aureus implicated for the long-term treatment in osteomyelitis and osteoporosis.

\subsection{Effect of m-HAs on human cells}

Toxicity issues are a major concern and are important factors in the context of materials used as regenerative medicine and tissue engineering; and interestingly, when some material which are known to be inert, in large quantities are in fact toxic at nanoscale. Employing such type of nanoparticles, which are toxic in nature over a longer period of time, could significantly diminish the therapeutic efficiency of the cell-based therapy. The dominating factors leading to the toxicity of nanoparticles on biological entities is highly dependent on a range and combination of factors related to the structural properties, dosage, and chemical composition of the particles. Toxic cellular effects are translated into impaired mitochondrial activity, membrane leakage, and morphological changes which can have adverse effects on cell viability, metabolic activity and can debilitate the therapeutic efficiency. Therefore, the application of such materials demands the preservation of physiological cellular properties without any impaired activity. This formulates the following question in our mind that whether these synthesized nanoparticles could be useful for in vitro and in vivo application? And in order to confirm so biocompatibility, cell adhesion/division and long term effect of these nanoparticles on cells were studied.

5.3.1 Biocompatibility test. Initially dose dependent MTT assay was done on MG-63 cell lines and it was seen that almost
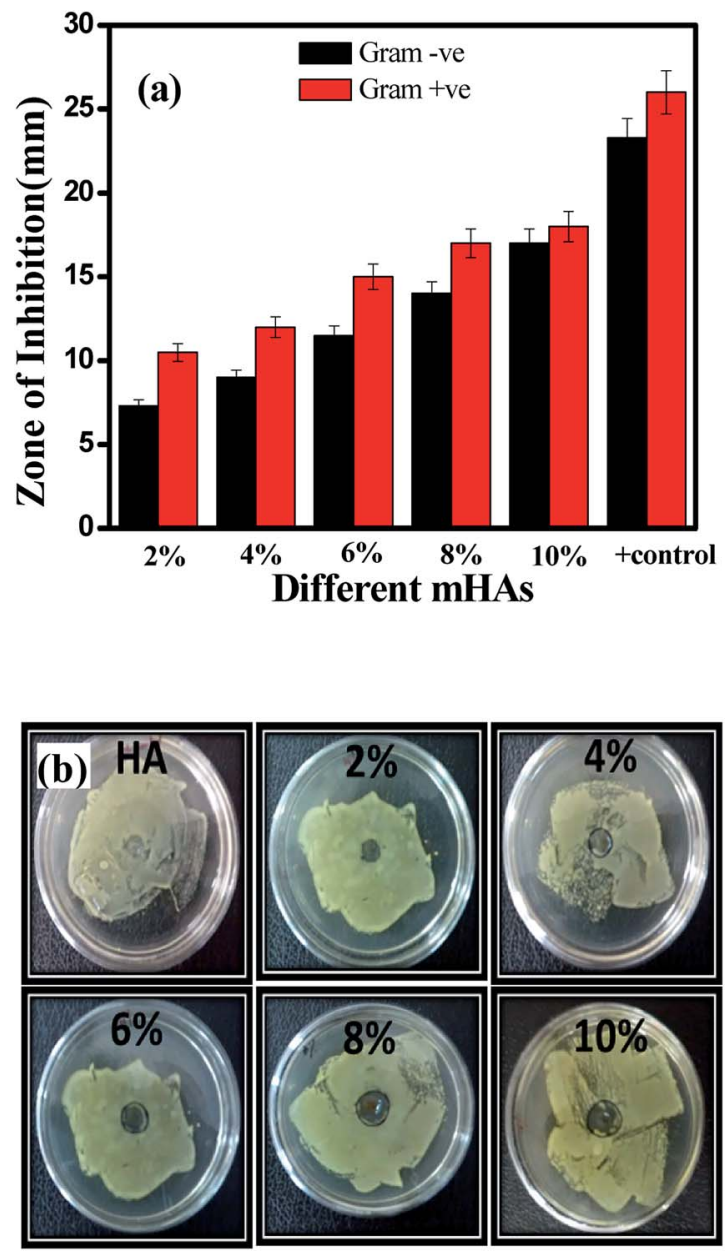

Fig. 9 Antibacterial activity of the synthesized nanoparticles (a) sample vs. zone of inhibition, (b) agar disc diffusion method. 
all the concentrations showed better performance than that of the control as shown in Fig. 10(a). The time dependent assay was conducted with $100 \mathrm{mg} \mathrm{ml}^{-1}$ of nanoparticle concentration and an overall increase in cell number was observed with increase in the iron concentration. The in vitro investigations indicated the enhanced biocompatibility, ability to support cell adhesion and division of these nanoparticles. The concentration of iron had a great influence on the cell behaviour and positively influenced cell adhesion and division in vitro compared to the non-magnetic control. Since MTT assays rely on a mitochondrial reductase to convert the tetrazole to formazan. The assumption is that the conversion is dependent on the number of viable cells but there is always the possibility that treatment of cells may result with increased enzymatic activity without actually having an effect on cell number or cell viability. That is why MTT experiment was complemented with simple cell counts (trypan blue exclusion assay) and we observed almost 2.5 times the cell viability after treatment with $10 \% \mathrm{~m}$ HA (Fig. 10(b)).

5.3.2 Cell morphology. In order to check the long term effect of nanoparticles on the morphology of MG-63 cells in due time, the cells were seeded and was allowed to grow for 21 days. Fig. 11 show osteoblasts after 21 days of culture in presence of different samples. Though there was no notable difference number in the morphology of the cells but an increase in the number of cells was evident with increase in the iron concentration.

Further, the SEM micrographs (Fig. 12) of the analysed cells show that they adhered well to the surfaces. Well-attached cells

(a)

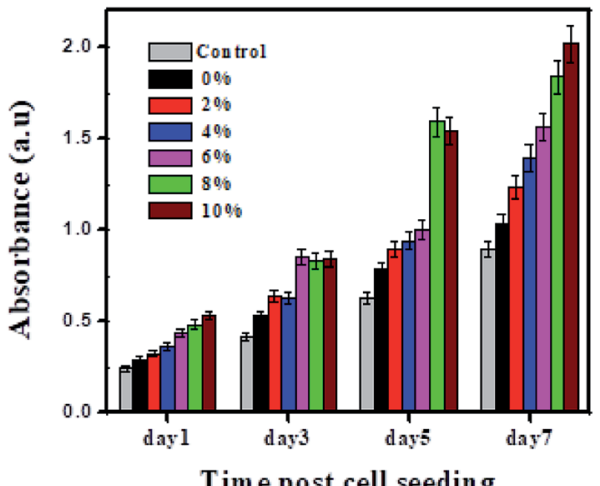

(b)

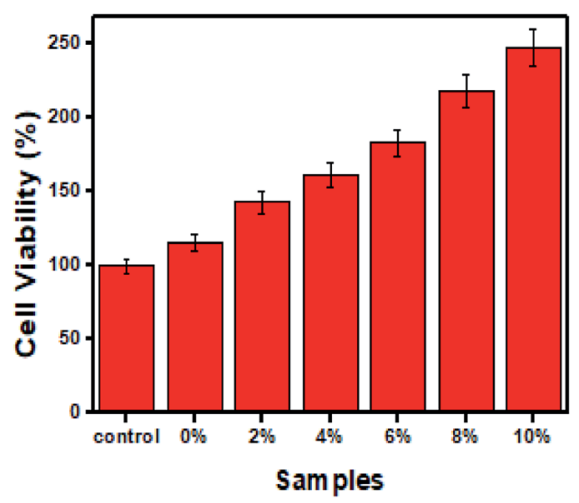

Fig. 10 (a) MTT Assay as a test of biocompatibility, (b) cell viability.

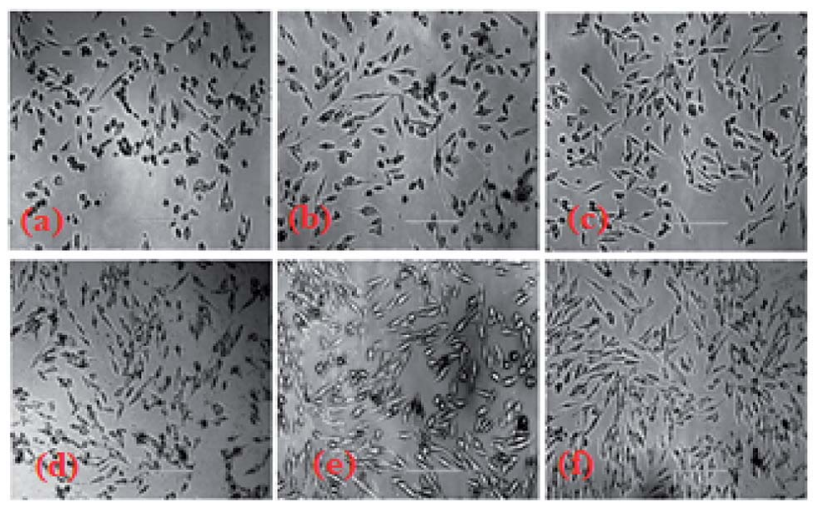

Fig. 11 Phase contrast image of change in cell morphology after 21 days(a) control, (b) $2 \%$, (c) $4 \%$, (d) $6 \%$, (e) $8 \%$ and (f) $10 \%$.

were progressively grown on the surface of the nanoparticles. Cells were more densely packed and showed higher spindle like structure, having good attachments to the surfaces of nano materials with increase in the iron concentration indicating the role of doped iron in the cell division. The importance of filopodia extension in presence of nanometer scale topography is clearly seen. Overall, the results suggest that it is not only the size of nanoparticles that decide the fate of these osteoblast, but also the concentration of iron plays an important role in the overall osteoblast functions like adhesion, division.

5.3.3 Cell size and granularity. The technique of Flow Cytometry (FCM) has become well established in a number of

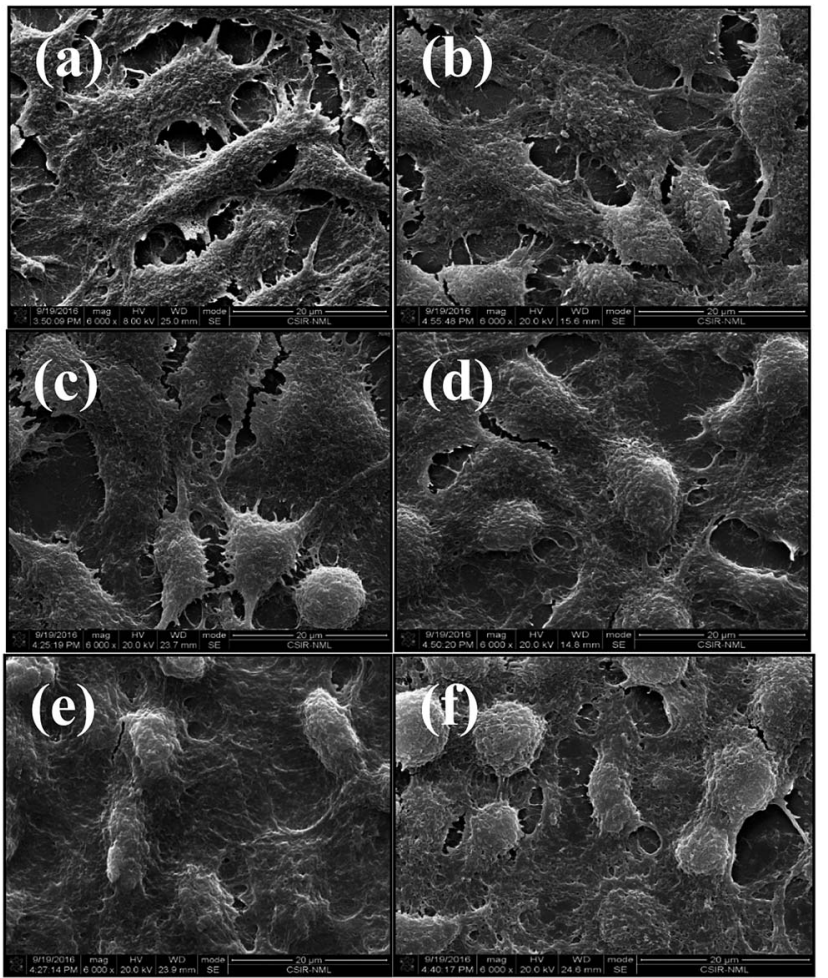

Fig. 12 Cell adhesion and growth on different nanoparticle (a) control, (b) $2 \%$, (c) $4 \%$, (d) $6 \%$, (e) $8 \%$ and (f) $10 \%$. 
biomedical and clinical areas. This actually detect the scattered and emitted light as particles in a suspension flow in a fluid stream pass a laser beam. The light scattering properties of FCM are used to assess differences in cell morphology, because at small angles (forward scattered, FSC) this is considered proportional to cell size and at orthogonal angles (side scatter, SSC) it is proportional to the granularity of the cell. Though this technique have little application in the field of biomaterials, however, we have used this technique to first examine the effect of these doped materials on osteoblast-like cell MG-63 compared to control sample.

Second, and most importantly, we utilized FCM to determine whether these materials have affected the size and granularity of the cells and the expression of connective tissue components that may at least partially indicate the potential effectiveness of the materials in vivo.

To measure the FSC and SSC light scattering properties of the cells, after 7 days of incubation, the disks and plastic surface were washed twice with PBS and the cells detached using trypsin-EDTA for $10 \mathrm{~min}$ at $37{ }^{\circ} \mathrm{C}$ followed by suspension in PBS. The FSC and SSC of 10000 individual cells were measured using a FAC Scan flow cytometer (BD LSR Fortessa) on a linear scale of 1024 channels.

FCM analysis of the size and granularity of the cells were carried out to determine whether the materials had any effect on the physical characteristics of the cells. Fig. 13 shows representative FSC and SSC dot plots of the MG-63 cells cultured with doped and control samples. Neither significant difference in the average size was apparent nor there much alteration in the cell morphology and granularity compared to the control suggesting no ill effect of these materials on cells.

5.3.4 Drug study. The drug release profile was tested for one of the most effective and widely used drug methotrexate for treating varied cancers and rheumatoid arthritis. Initial burst release was observed in control HA, which eventually showed sustained and controlled release with increase in the iron content as shown in Fig. 14. In order to understand the nature of the release profile the diffusion coefficients of each samples
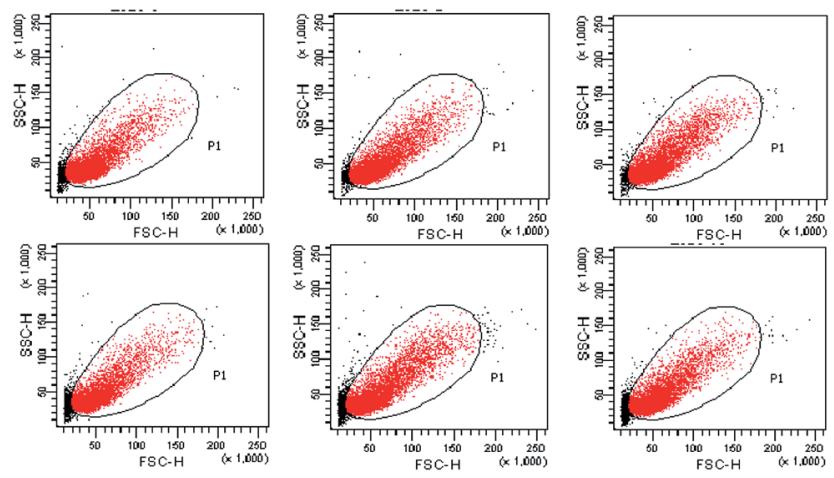

Fig. 13 Representative FCM dot plot profiles of 10000 individual MG63 cells grown for 7 days, showing the FSC and SSC distribution of the cells from 0 to $10 \%$ respectively. Each dot represents a single particle. The region has been selected so as to include only single, intact cells for analysis of FSC, SSC. were calculated as described in Section 3. Fig. 15 is the linear fitting of the initial $8 \mathrm{~h}$ release profile data with square root of time from where the slope values were obtained followed by calculation of the diffusion coefficients. The values of the diffusion coefficients were tabulated in Table 4 . It can be seen that the value of diffusion coefficients decreases significantly as function of doping. This further accentuates the change of burst release profile into controlled release upon doping. Further, in order to draw more insight about the mechanism governing the release profile we have fitted the release data with the equation derived from the mathematical model (details in $\mathrm{ESI} \dagger$ ). However, the experimental data fitted well using the derived equation up to initial $8 \mathrm{~h}$ and deviates after that. Therefore, a second term is introduced in the equation as below:

$$
\frac{M_{t}}{M_{\infty}}=K_{1} t^{0.5}+K_{2} t^{n}
$$

where,

$$
K_{1}=\sqrt{\frac{243 C_{\mathrm{S}} D_{\mathrm{d}}}{40 a^{\mathrm{o}^{2}} A}}
$$

While the value of $K_{2}$ and $n$ are calculated from fitting results that tells about the mechanism of release at higher time. It is to be noted from the Fig. 14 that the initial burst release decreases significantly upon doping with iron. A careful observation of the fitting results predicts that the complete release is governed by the combination of two type of mechanism. Initially the release is governed by the Fickian release mechanism (following Fick's law) while for longer time it is the anomalous transport that takes over up to $6 \% \mathrm{~m}-\mathrm{HA}$ while beyond $6 \%$ super case-II transport dominates over. ${ }^{\mathbf{4 8 , 4 9}}$ In case of the control HA the contribution of Fickian mechanism is significant and hence burst release is observed. However, with increase in doping concentration the Fickian contribution decreases and, hence burst releases are turned in to much control and sustain one. Significant decrease in the drug release with increase in the iron concentration may be attributed to the strong binding between them.

It might be that $\mathrm{Fe}^{3+}$ ions are in a covalent interaction with the drug moiety and thereby delaying the release of the latter by

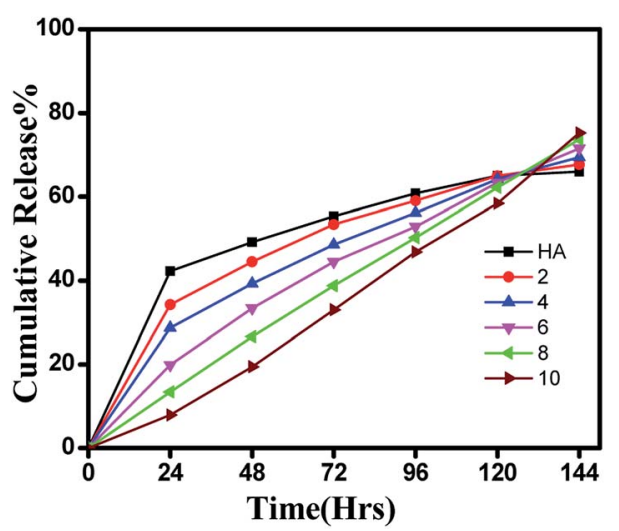

Fig. 14 Drug release profile of control and m-HA. 

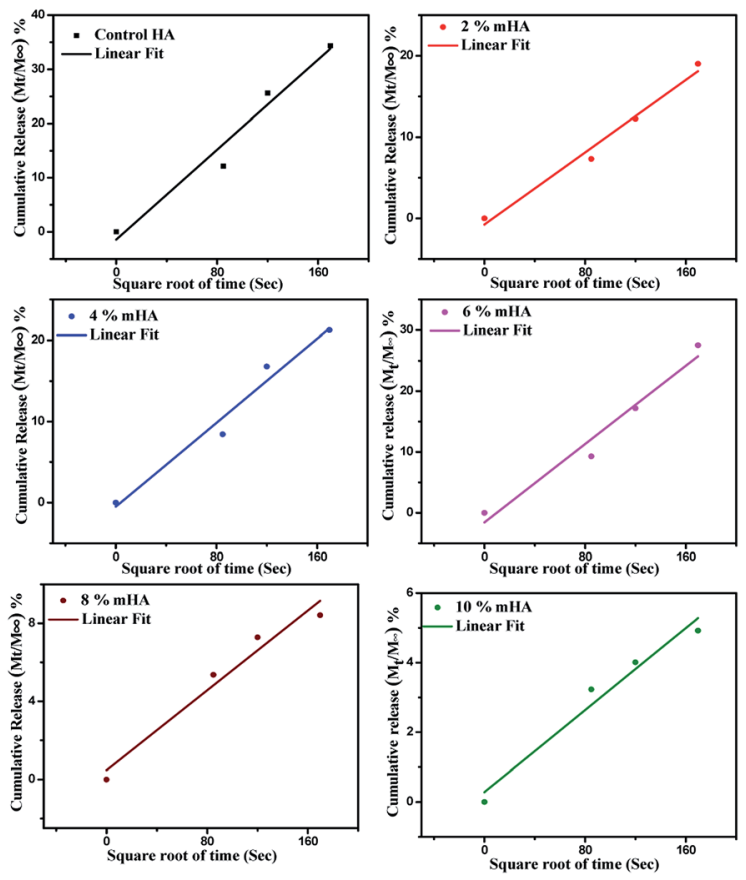

Fig. 15 Linear fitting of the drug release data for initial $8 \mathrm{~h}$.

Table 4 Parameters of the drug release fitting

\begin{tabular}{llll}
\hline Sample & $D\left(\mathrm{~cm}^{2} \mathrm{~s}^{-1}\right) \times 10^{-4}$ & $K_{2}$ & $n$ \\
\hline Control HA & 3.64 & 0.0467 & 0.40 \\
$2 \%$ m-HA & 2.11 & 0.0088 & 0.67 \\
$4 \%$ m-HA & 1.39 & 0.0072 & 0.69 \\
$6 \%$ m-HA & 1 & 0.0041 & 0.77 \\
$8 \%$ m-HA & 0.21 & 0.00013 & 1.29 \\
$10 \%$ m-HA & 0.007 & 0.00014 & 1.72
\end{tabular}

hindering the movement of drug molecules. And, with increase in $\mathrm{Fe}^{3+}$ concentration the drug might have more accessibility bond to $\mathrm{Fe}^{3+}$ rather than $\mathrm{HA}$ further delaying the release through increased resistance. Hence, it is proved that bonding of both HA and iron with the drug could be important to ensure delayed release. Thus, these substituted nanoparticles could serve as a sustained release depot (an injection that releases its active compound in a consistent way over a long period of time) for methotrexate. This type of sustained drug release for cancer chemotherapy could probably circumvent drug resistance, an important impediment in cancer therapy. Further, the total amount of drug administered can be reduced, thus maximizing availability with minimum dose, minimizing or eliminating local and systemic side effects, minimizing drug accumulation with chronic dosing, safety margins of high potency drugs can be increased and the incidence of both local and systemic adverse side effects can be reduced in sensitive patients. And, since there is improvement in efficiency in the treatment, it leads to cure or control condition more promptly. The concentration of iron is not the only factor that contributes to the increased release but the size also play the role here as we see that as the concentration of dopant increases, the size decreases and the drug releasing capability increases.

\section{Conclusion}

The ease of atomic doping and the possibility of high ionic promiscuity in hydroxyapatite and on top of this it's one pot green synthesis make it amenable to a variety of application. This proposition exemplifies through room temperature biomimetically nano-engineered m-HA, wherein physiochemical and biological property evaluation has been meticulously carried out. XRD results substantiate the empirical evidence of iron doping in terms of decrease in crystallite size, and increase in compressive strain and energy density, with increasing dopant concentration. And, this concurs with the results of Rietveld refinement and TEM, thus confirming that $10 \%$ iron could be isomorphously doped into hydroxyapatite crystal structure. Beside this, more sustained and controlled drug release with increased iron concentration has also been observed. Fickian and anomalous transport found to be pronounced mechanism for drug release, which was elucidated using a mathematical model developed for calculating drug diffusivity. Furthermore, these nanoengineered particles possess excellent anti-bacterial property, enhanced bio-activity (more than 2-fold increase in cell viability) and non-toxicity which holistically complement its significance in various biomedical applications. Thus, the avenues where these nanoparticles hold an immense potential are bioactive coatings, bone repairing and cancer treatment, site specific drug delivery and bone tissue engineering.

\section{Conflicts of interest}

There are no conflict of interest to declare in this work.

\section{Acknowledgements}

The authors would like to thank the CSIR-Ministry of Science and Technology and ESC-103 for their financial support. Lubna Sheikh acknowledges DST for the INSPIRE Fellowship.

\section{References}

1 N. Sykaras, A. M. Iacopino, V. A. Marker, R. G. Triplett and R. D. Woody, Implant Materials, Designs, and Surface Topographies: Their Effect on Osseointegration. A Literature Review, The International Journal of Oral \& Maxillofacial Implants, 2000, 15, 675-690.

2 G. C. Padovani, V. P. Feitosa, S. Sauro, F. R. Tay, G. Durán, A. J. Paula and N. Duran, Advances in Dental Materials through Nanotechnology: Facts, Perspectives and Toxicological Aspects, Trends Biotechnol., 2015, 33, 621-636.

3 S. D. Cook, K. A. Thomas, J. F. Kay and M. Jarcho, Hydroxyapatite-Coated Titanium for Orthopedic Implant Applications, Clin. Orthop. Relat. Res., 1988, 232, 225-243.

4 M. S. Abu Bakar, M. H. W. Cheng, S. M. Tang, S. C. Yu, K. Liao, C. T. Tan, K. A. Khor and P. Cheang, Tensile 
properties, tension-tension fatigue and biological response of polyetheretherketone-hydroxyapatite composites for load-bearing orthopaedic implants, Biomaterials, 2003, 24, 2245-2250.

5 H. W. Kim, J. C. Knowles and H. E. Kim, Hydroxyapatite/ poly( $\varepsilon$-caprolactone) composite coatings on hydroxyapatite porous bone scaffold for drug delivery, Biomaterials, 2004, 25, 1279-1287.

6 K. Agrawal, G. Singh, D. Puri and S. Prakash, Synthesis and Characterization of Hydroxyapatite Powder by Sol-Gel Method for Biomedical Application, J. Miner. Mater. Charact. Eng., 2011, 10, 727-734.

7 S. V. Dorozhkin, Calcium orthophosphates, Biomatter, 2011, 1, 121-164.

8 A. Singh, Hydroxyapatite, a biomaterial: its chemical synthesis, characterization and study of biocompatibility prepared from shell of garden snail, Helix aspersa, Bull. Mater. Sci., 2012, 35, 1031-1038.

9 Z. Wang, Z. Xu, W. Zhaoa and N. Sahai, A potential mechanism for amino acid controlled crystal growth of hydroxyapatite, J. Mater. Chem. B, 2015, 3, 9157-9167.

10 K. Yamashita, H. Owada, H. Nakagawa, T. Umegaki and T. Kanazawa, Trivalent-Cation-Substituted Calcium Oxyhydroxyapatite, J. Am. Ceram. Soc., 1986, 69, 590-594.

11 T. Kokubo, H. M.Kim and M. Kawashita, Novel bioactive materials with different mechanical properties, Biomaterials, 2003, 24, 2161-2175.

12 Z. Hong, P. Zhang, C. He, X. Qiu, A. Liu, L. Chen, X. Chen and X. Jing, Nano-composite of poly(l-lactide) and surface grafted hydroxyapatite: Mechanical properties and biocompatibility, Biomaterials, 2005, 26, 6296-6304.

13 L. Sheikh, S. Tripathy and S. Nayar, Biomimetic matrix mediated room temperature synthesis and characterization of nanohydroxypatite towards targeted drug delivery, $R S C$ Adv., 2016, 6, 62556-62571.

14 R. Karunamoorthi, G. S. Kumar, A. I. Prasad, R. K. Vatsa, A. Thamizhavel and E. K. Girija, Fabrication of a novel biocompatible magnetic biomaterial with hyperthermia potential, J. Am. Ceram. Soc., 2014, 97, 1115-1122.

15 K. Donadel, M. D. V. Felisberto and M. C. M. Laranjeira, Preparation and characterization of hydroxyapatite-coated Iron oxide particles by spray-drying technique, An. Acad. Bras. Cienc., 2009, 81, 179-186.

16 H. C. Wu, T. W. Wang, F. H. Lin and J. S. Sun, Characterization of Magnetic Hydroxyapatite Nanocrystallites and Potential Application for MRI Contrast Agent, Curr. Nanosci., 2011, 7, 902-907.

17 F. Witte, F. Feyerabend, P. Maier, J. Fischer, M. Störmer, C. Blawert, W. Dietzel and N. Hort, Biodegradable magnesium-hydroxyapatite metal matrix composites, Biomaterials, 2007, 28, 2163-2174.

18 S. Dasgupta, A. Bandyopadhyay and S. Bose, $\mathrm{Zn}$ and $\mathrm{Mg}$ Doped Hydroxyapatite Nanoparticles for Controlled Release of Protein, Langmuir, 2010, 26, 4958-4964.

19 D. Choi, K. G. Marra and P. N. Kumta, Chemical synthesis of hydroxyapatite/poly(3-caprolactone) composites, Mater. Res. Bull., 2004, 39, 417-432.
20 I. R. Gibson, J. Huang, S. M. Best and W. Bonfield, Enhanced in vitro cell activity and surface apatite layer formation on novel silicon-substituted hydroxyapatites, in (Proceedings) the 12th International Symposium on Ceramics in Medicine, World Scientific, 2009, pp. 191-194.

21 A. M. Pietak, J. W. Reid, M. J. Stott and M. Sayer, Silicon substitution in the calcium phosphate bioceramics, Biomaterials, 2007, 28, 4023-4032.

22 E. Boanini, M. Gazzano and A. Bigi, Ionic substitutions in calcium phosphates synthesized at low temperature, Acta Biomater., 2010, 6, 1882-1894.

23 A. Bigi, E. Boanini, C. Capuccini and M. Gazzano, Strontiumsubstituted hydroxyapatite nanocrystals, Inorg. Chim. Acta, 2007, 360, 1009-1016.

24 B. Badraoui, A. Bigi, M. Debbabi, M. Gazzano, N. Roveri and R. Thouvenot, Physicochemical Properties and Structural Refinement of Strontium-Lead Hydroxyapatites, Eur. J. Inorg. Chem., 2002, 7, 1864-1870.

25 M. I. Kay, R. A. Young and A. S. Posner, Crystal Structure of Hydroxyapatite, Nature, 1964, 204, 1050-1052.

26 T. J. Webster, C. Ergun, R. H. Doremus and R. Bizios, Hydroxylapatite with substituted magnesium, zinc, cadmium, and yttrium II: mechanisms of osteoblast adhesion, J. Biomed. Mater. Res., 2002, 59, 312-317.

27 A. Ito, H. Kawamura, S. Miyakawa, P. Layrolle, R. Aomori and S. Tsutsumi, Resorbability reduction by the incorporation of zinc into tricalcium phosphate, Key Eng. Mater., 2001, 199, 192-202.

28 C. M. Serre, M. Papillard, P. Chavassieux, J. C. Voegel and G. Boivin, Influence of magnesium substitution on a collagen-apatite biomaterial on the production of a calcifying matrix by human osteoblasts, J. Biomed. Mater. Res., 1998, 42, 626-633.

29 C. H. Hou, S. M. Hou, Y. S. Hsueh, J. Lin, H. C. Wu and F. H. Lin, The in vivo performance of biomagnetic hydroxyapatite nanoparticles in cancer hyperthermia therapy, Biomaterials, 2009, 30, 3956-3960.

30 V. S. Chandra, G. Baskar, R. V. Suganthi, K. Elayaraja, M. I. A. Joshy, W. S. Beaula, R. Mythili, G. Venkatraman and S. N. Kalkura, Blood Compatibility of Iron-Doped Nanosize Hydroxyapatite and Its Drug Release, ACS Appl. Mater. Interfaces, 2012, 4, 1200-1210.

31 A. Tampieri, T. D'Alessandro, M. Sandri, S. Sprio, E. Landi, L. Bertinetti, S. Panseri, G. Pepponi, J. Goettlicher, M. B. López and J. Rivas, Intrinsic magnetism and hyperthermia in bioactive Fe-doped hydroxyapatite, Acta Biomater., 2012, 8, 843-851.

$32 \mathrm{M}$. Sato and A. Nakahira, Influence of $\mathrm{Fe}$ addition to hydroxyapatite by aqueous solution process, J. Ceram. Soc. Jpn., 2013, 121, 422-425.

33 J. Terra, G. B. Gonzalez, A. M. Rossi, J. G. Eon and D. E. Ellis, Theoretical and experimental studies of substitution of cadmium into hydroxyapatite, Phys. Chem. Chem. Phys., 2010, 12, 15490-15500.

34 J. A. Wasastjerna, On the radii of ions, Comm. Phys.-Math., Soc. Sci. Fenn., 1923, 1, 1-25. 
35 N. Ignjatovic, Z. Ajdukovic, V. Savic, S. Najman, D. Mihailovic, P. Vasiljevic, Z. Stojanovic, V. Uskokovic and D. Uskokovic, Nanoparticles of cobalt-substituted hydroxyapatite in regeneration of mandibular osteoporotic bones, J. Mater. Sci.: Mater. Med., 2013, 24, 343-354.

36 L. Veselinovic, L. Karanovic, Z. Stojanovic, I. Bracko, S. Markovic, N. Ignjatovic and D. Uskokovic, Crystal structure of cobalt-substituted calcium hydroxyapatite nanopowders prepared by hydrothermal processing, $J$. Appl. Crystallogr., 2010, 43, 320-327.

37 N. S. Goncalves, J. A. Carvalho, Z. M. Lima and J. M.Sasaki, Size-strain study of NiO nanoparticles by X-ray powder diffraction line broadening, Mater. Lett., 2012, 72, 36-38.

38 A. K. Zak, W. H. Abd Majid, M. E. Abrishami and R. Yousefi, $\mathrm{X}$-ray analysis of $\mathrm{ZnO}$ nanoparticles by Williamson-Hall and size-strain plot methods, Solid State Sci., 2011, 13, 251-256.

39 C. D. Wagner, W. M. Riggs, L. E. Davis and J. F. Moulder, Handbook of X-ray Photoelectron Spectroscopy, ed. G. E. Muilenberg, Perkin-Elmer Corporation, 1st edn, 1979.

40 F. P. Filho, R. E. F. Q. Nogueira, M. P. F. Graca, M. A. Valente, A. S. B. Sombra and C. C. Silva, Structural and mechanical study of the sintering effect in hydroxyapatite doped with iron oxide, Phys. B, 2008, 403, 3826-3829.

41 I. Cacciotti, A. Bianco, M. Lombardi and L. Montanaro, Mgsubstituted hydroxyapatite nanopowders: Synthesis, thermal stability and sintering behaviour, J. Eur. Ceram. Soc., 2009, 29, 2969-2978.
42 K. H. Zuo, Y. P. Zeng and D. Jiang, Synthesis and Magnetic Property of Iron Ions-Doped Hydroxyapatite, J. Nanosci. Nanotechnol., 2012, 12, 7096-7100.

43 V. S. Chandra, K. Elayaraja, K. Thanigaiarul, S. Ferraris, S. Spriano, M. Ferraris, K. Asokan and S. N. Kalkura, Synthesis of magnetic hydroxyapatite by hydrothermalmicrowave technique: Dielectric, Protein Adsorption, Blood compatibility and Drug release studies, Ceram. Int., 2015, 41, 13153-13163.

44 A. G. Kolhatkar, A. C. Jamison, D. Litvinov, R. C. Willson and T. R. Lee, Tuning the Magnetic Properties of Nanoparticles, Int. J. Mol. Sci., 2013, 14, 15977-16009.

45 A. Azam, A. S. Ahmed, O. Mohammad, M. S. Khan, S. S. Habib and A. Memic, Antimicrobial activity of metal oxide nanoparticles against Gram-positive and Gramnegative bacteria: a comparative study, Int. J. Nanomed., 2012, 7, 6003-6009.

46 N. Tran, A. Mir, D. Mallik, A. Sinha, S. Nayar and T. J. Webster, Bactericidal effect of iron oxide nanoparticles on Staphylococcus aureus, Int. J. Nanomed., 2010, 5, 277.

47 J. T. Seil and T. J. Webster, Antimicrobial applications of nanotechnology: methods and literature, Int. J. Nanomed., 2012, 7, 2767-2781.

48 P. Costa and J. M. S. Lobo, Modelling and comparison of dissolution profiles, Eur. J. Pharm. Sci., 2001, 13, 123-133.

49 J. Siepmann and N. A. Peppas, Higuchi equation: Derivation, applications, use and misuse, Int. J. Pharm., 2011, 418, 6-12. 